\title{
Numerical Study on the Influence of Fault on the Seepage and Stress Field of Formation
}

\author{
${ }^{1,2}$ Yongxiang Zheng, ${ }^{1,2}$ Jianjun Liu, ${ }^{1,2}$ Bohu Zhang and ${ }^{1,2}$ Yue Sun

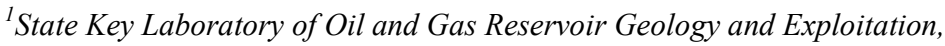 \\ Southwest Petroleum University, Chengdu, China \\ ${ }^{2}$ School of Geoscience and Technology, Southwest Petroleum University, Chengdu, China
}

Article history

Received: 06-01-2017

Revised: 08-01-2017

Accepted: 24-01-2017

Corresponding Author:

Jianjun Liu

State Key Laboratory of Oil

and Gas Reservoir Geology and

Exploitation, Southwest

Petroleum University,

Chengdu, China and

School of Geoscience and

Technology, Southwest

Petroleum University,

Chengdu, China

Email: liujj0906@163.com

\begin{abstract}
In the process of water injection in oil field, the fault will affect the seepage field and stress field of the formation, which leads to the deformation and destruction of the formation. Therefore, more casing damage wells are found around the fault. In order to study the influence of fault on the formation in the process of water injection, a reservoir model including one closed fault was established based on the fluid-solid coupling method and the characteristics of seepage field and stress field near the fault were studied. The results show that the closed fault will obstruct the flow path of the fluid in the formation, resulting in the independence of the seepage and stress characteristics on both sides of the fault. The pore pressure and formation stress of injection side of fault are higher than that of production side and bigger shear stress is observed at the junction between the fault and the permeable stratum.
\end{abstract}

Keywords: Seepage, Fault, Fluid Solid Coupling, Water Injection, Numerical Simulation

\section{Introduction}

Water injection is a common method to maintain formation pressure and improve oil recovery. With the time increase of water injection, serious casing damage occurred in many oilfields. The casing damage near fault is particularly serious. Therefore, a series of studies have been carried out on the casing damage of oil field. A series of experiments and numerical simulations are carried out to study the casing damage mechanism of the casing, the creep of the mud and fault flow by using the multi field coupling method by researchers (Xiaolan et al., 2009; Ji et al., 2011; Xianbin et al., 2015; Jianjun et al., 2013; Xiangfeng, 2009; Chao, 2009). In addition, the casing damage mechanism of high pressure water injection is analyzed by Xiuting et al. (2010) with the example of Daqing oilfield. Combined with the practical experience in the field, Qingbing et al. (2011) analyzed the causes of casing damage in oil and water wells and put forward the corresponding prevention and control measures. However, most of the studies are based on the study of the deformation without considering the influence of fault on casing damage.

The study of fault mainly focuses on the mechanism of fault activation and propagation. Elli et al. (2015) carried out a study on the brittle fracture and extension of sandstone fault and Sun et al. (2015) studied about the crack propagation of unsaturated sandstone fracture during water injection. In addition, the water inrush from fault with THM coupling theory was studied by Liping et al. (2011). The activation and expansion of fault is the main cause of fault slip and casing failure. The stress field and seepage field around the fault are the basic conditions of fault activation. Therefore, in order to study the influence of fault on casing damage, the seepage and stress distribution near the fault should be determined. Zanjani et al. (2016) carried out a research to simulate the seepage stress field around the fault in the dam using Abaqus software. Besides, the characteristics of the seepage field around the fault of the offshore oil field are studied by Hongjie et al. (2015). The geomechanic problem for reservoir is a hot issue and an urgent problem to be solved for a long time (Guang, 2016; Hua et al., 2016; Jalali et al., 2016; Jianjun et al., 2014; Rui et al., 2016).

In order to further clarify the influence of fault on oil seepage water flooding process, understand the seepage near faults and stress distribution, this paper established the stratum model containing faults, to study the influence of fault during water flooding. The distribution of the pressure field and the stress field around the fault are 
analyzed. The research in this study provide reference significance for the analysis of casing damage near fault.

\section{Model and Experiment}

\section{Mathematical Model}

The mathematical model of the stress and strain field of fluid-solid coupling theory of the continuous medium under the condition of vertical compression and permeability change is as follows:

$\frac{3 K_{V}\left(\sigma_{e}\right)+G\left(\sigma_{e}\right)}{3} \frac{\partial \varepsilon_{V}}{\partial i}-G \nabla^{2} u_{i}+\frac{\partial p}{\partial i}-F_{i}=0$

and:

$$
K_{V}\left(\sigma_{e}\right)=\frac{E\left(\sigma_{e}\right)}{3(1-2 v)}, G\left(\sigma_{e}\right)=\frac{E\left(\sigma_{e}\right)}{2(1-2 v)}
$$

Where:

$K_{V}=$ The volume elastic modulus (KPa)

$G=$ The shear modulus $(\mathrm{KPa})$

$\sigma_{e}=$ The effective stress $(\mathrm{KPa})$

$\varepsilon_{v}=$ The volume strain (1)

$p=$ The pore pressure $(\mathrm{KPa})$

$F_{i}=$ The stress of body $(\mathrm{KPa})$

$E=$ The elastic modulus $(\mathrm{KPa})$

$v=$ The passion's ratio (1)

Due to $E=E\left(\sigma_{e}\right)$ is a function of effective stress, so $K_{V}\left(\sigma_{e}\right)$ and $G\left(\sigma_{e}\right)$ are the function of effective stress. The mathematical model of seepage field is as follows:

$\nabla \cdot\left[\frac{k\left(\sigma_{e}\right)}{\mu} \cdot \nabla(p+\rho g z)\right]=n\left(\sigma_{e}\right) \beta_{p} \frac{\partial p}{\partial t}-\frac{\partial \varepsilon_{V}}{\partial t}$

Where:

$k=$ The permeability $(\mathrm{mD})$

$\mu=$ The dynamic viscosity coefficient (cp)

$\rho=$ The density of fluid $\left(\mathrm{kg} / \mathrm{m}^{3}\right)$

$g=$ The gravitational acceleration, $9.8 \subseteq 10^{-3} \mathrm{~kg} /\left(\mathrm{m}^{2} \cdot \mathrm{s}^{2}\right)$

$z=$ The potential head $(\mathrm{m})$

$n=$ The porosity (1)

$\beta=$ The correction factor (1)

And $k=k\left(\sigma_{e}\right), n=n\left(\sigma_{e}\right)$. Both of them are function of effective stress. Equation 3 and 4 describe the relationship of stress and seepage:

$$
\begin{aligned}
& k\left(\sigma_{e}\right)=k_{0} \exp \left(-\alpha_{1} \sigma_{e}\right) \\
& n\left(\sigma_{e}\right)=n_{0} \exp \left(-\alpha_{2} \sigma_{e}\right)
\end{aligned}
$$

Where:

$k_{0}=$ The initial permeability $(\mathrm{mD})$ $n_{0}=$ The initial porosity (1)

$\alpha=$ An undetermined coefficient (1)

According to effective stress theory, the effective stress is related to total stress and pore pressure of reservoir, which is described by Equation 5:

$$
\sigma_{e}=\sigma-\alpha p
$$

where, $\sigma$ is the total stress $(\mathrm{KPa})$

According to Hooke's elastic law:

$\sigma_{e}=E\left(\sigma_{e}\right) \varepsilon_{\mathrm{V}}$

Combined Equation 1 6 with the boundary condition and initial condition, the mathematical model is described based on fluid-solid coupling theory.

\section{Numerical Model}

In order to study the influence of fault on the seepage flow, a model concluding a producing well and a water injection well is shown in Fig. 1. A closed fault $(B, G)$ is set up between the wells and the porosity and permeability of the fault are set to 0 . A water injection well is arranged at the lower left corner of the model. A producing well is set up in the upper right corner. Similarly, in order to study the influence of fault on the seepage field, a contrast model without fault is established. The other settings of model without fault are the same as those of fault model. As the water injection will destroy the original distribution of the pressure field and cannot maintain the stability of the initial injection, this paper simulated the results of 5 years after the formation of water injection when the reservoir achieves at a relatively stable state.

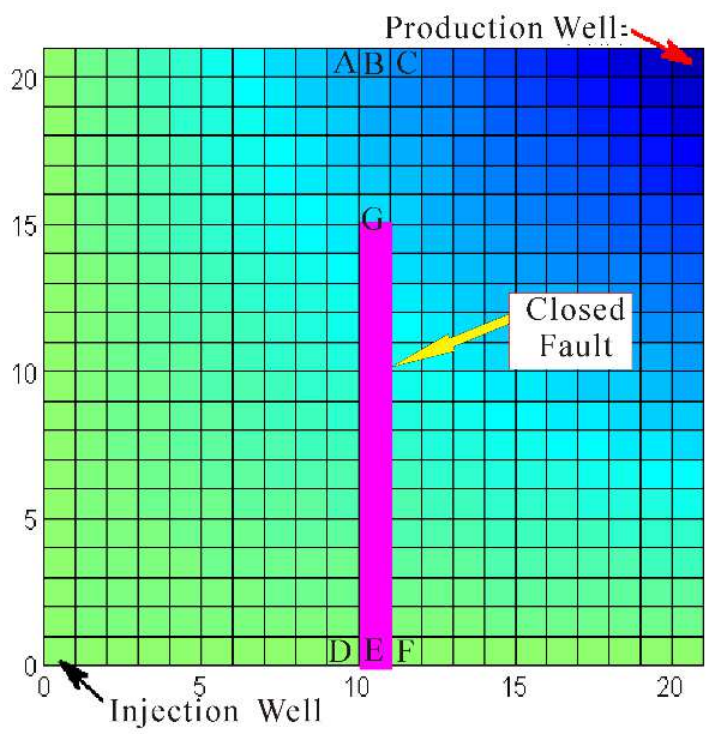

Fig. 1. Numerical model 


\section{Results and Analyses}

\section{Analysis of the Influence of Fault on Seepage Field and Stress Field}

\section{Effect of Fault on Fluid Seepage Path}

Closed fault will cut off the flow path of the fluid and influence the seepage field of the fluid. Figure 2a is the migration path of the fluid in a formation without fault. It can be seen that a symmetrical fluid pathway forms between the injection well and the oil well. Figure $2 \mathrm{~b}$ is the seepage path in the formation with a closed fault. The fault blocks the normal flow path of the fluid in the formation. So the fault blocks the normal flow path of the fluid in the formation and a new migration path from the injection well to the production well forms. Thus, the fault blocks the flow path of the fluid and increases the length of the flow path between the oil and water wells. The heterogeneity of formation seepage increases the complexity of the seepage field, which is not conducive to the formation pressure control.

\section{Effect of Fault on Pore Pressure}

The uneven distribution of seepage field caused by the change of flow path in the flow field will cause the imbalance of pore pressure distribution. Figure 3 shows the distribution of pore pressure. It can be seen from (a) that the pore pressure of the formation around the injection well is the largest and the pore pressure around the production well is the smallest. Because of the existence of faults, the formation pressure is discontinuous on both sides of the fault. The pore pressure of injection well is higher than that of oil well. However, the pore pressure on the side of the production well is basically balanced and there is a great change in the injection side. It can be seen from the figure (b) that

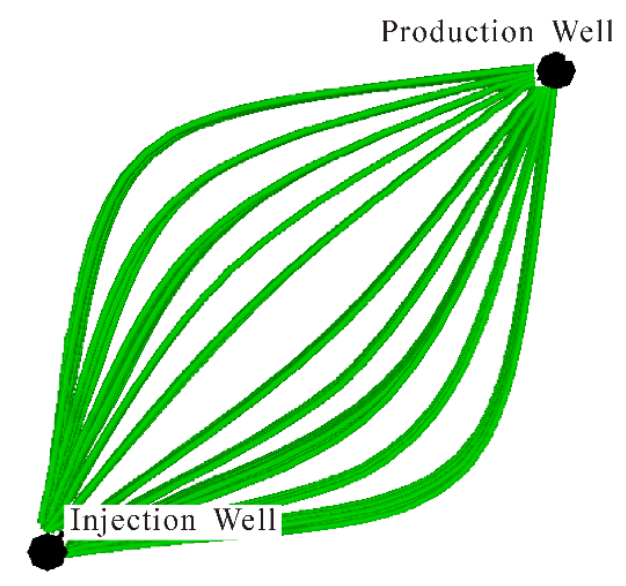

(a) a large pressure gradient occurs around the sides of the fault, water injection wells and oil wells. When the pressure difference near the two sides of the fault reaches the critical value, the fault will be activated and slide, leading to a large area of casing damage around the fault (Qingbing et al., 2011). The pressure difference near the water injection wells and producing wells is mainly caused by liquid injection and recovery in the wellbore. The pressure difference on both sides of the fault is caused by the permeability of the fault, which makes the seepage characteristics on both sides of the fault independent of each other.

\section{Effect of Fault on Stress Field}

Fault is the main cause of the heterogeneity of seepage field and pressure distribution. Coupling with the influence of injection and production, the stress in the formation also shows a strong imbalance. According to Fig. 4a, the distribution of ground stress is also related to fault. The stress of the injection side is greater than that of the production side. The value of ground stress around the injection well is the largest, while the minimum value of the ground stress is near the fault in the oil wells and oil wells. The pore pressure due to high injection pressure increases gradually, which results in the increase of total geostress. However, the side of the fault (one side of the producing well) is not affected, so the value of ground stress is low and it is relatively balanced. The Fig. $4 \mathrm{~b}$ illustrates that the gradient is large near the injection well and faults. The dependent field of seepage and stress induced by sealing of fault gives the reason for the big stress difference on the two sides of fault. Deformation or destruction may would occur when stress reach the critical value, which may result in seriously casing damage.

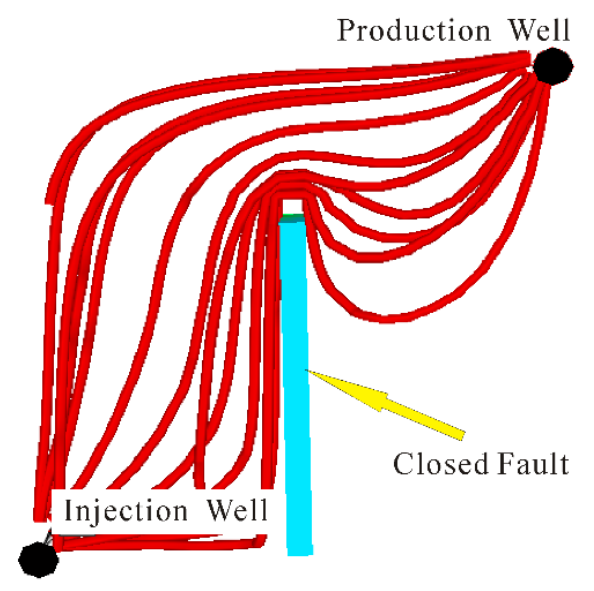

(b)

Fig. 2. The seepage pathway affected by faults 


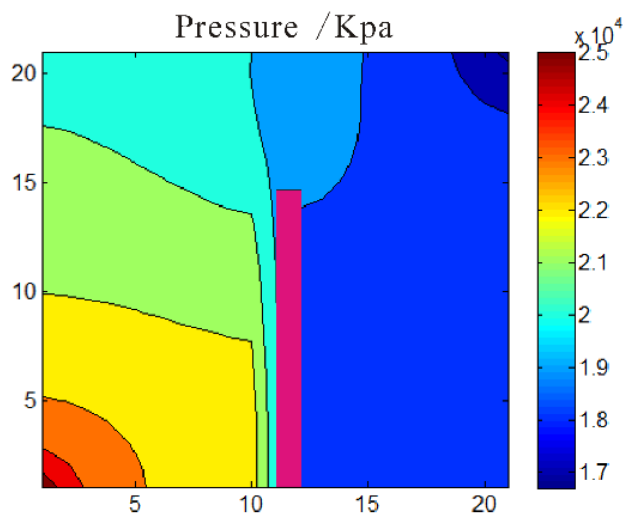

(a)

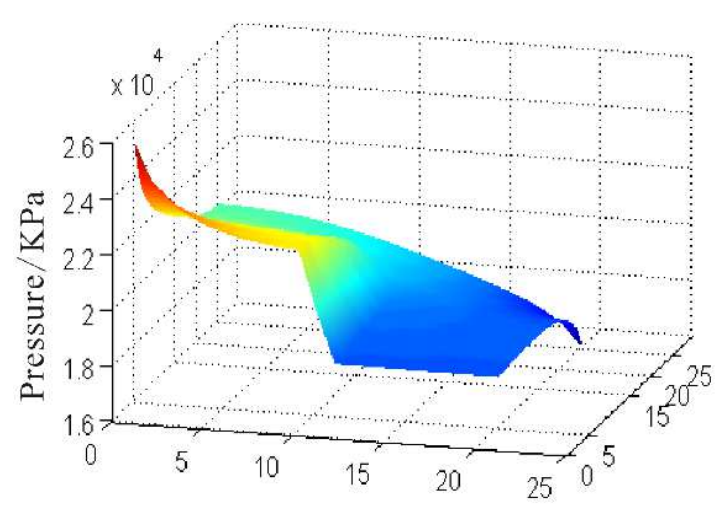

(b)

Fig. 3. Pore pressure affected by fault

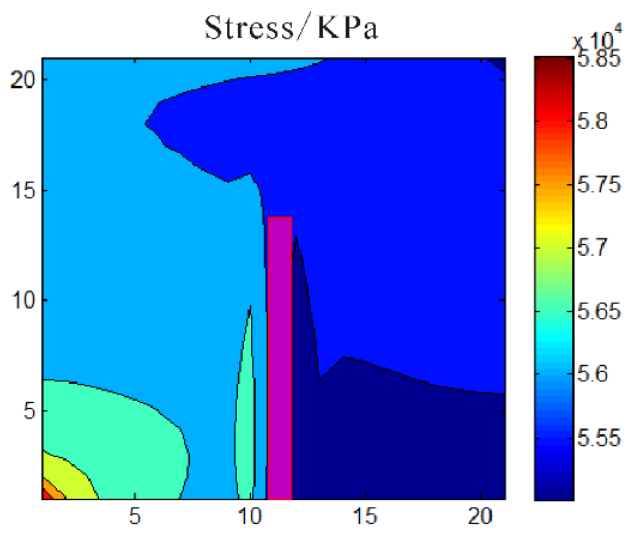

(a)

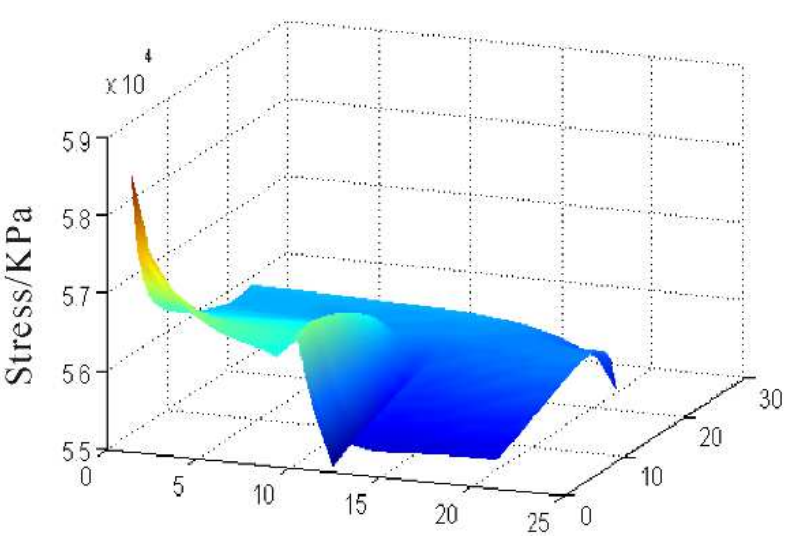

(b)

Fig. 4. Geo-stress affected by fault

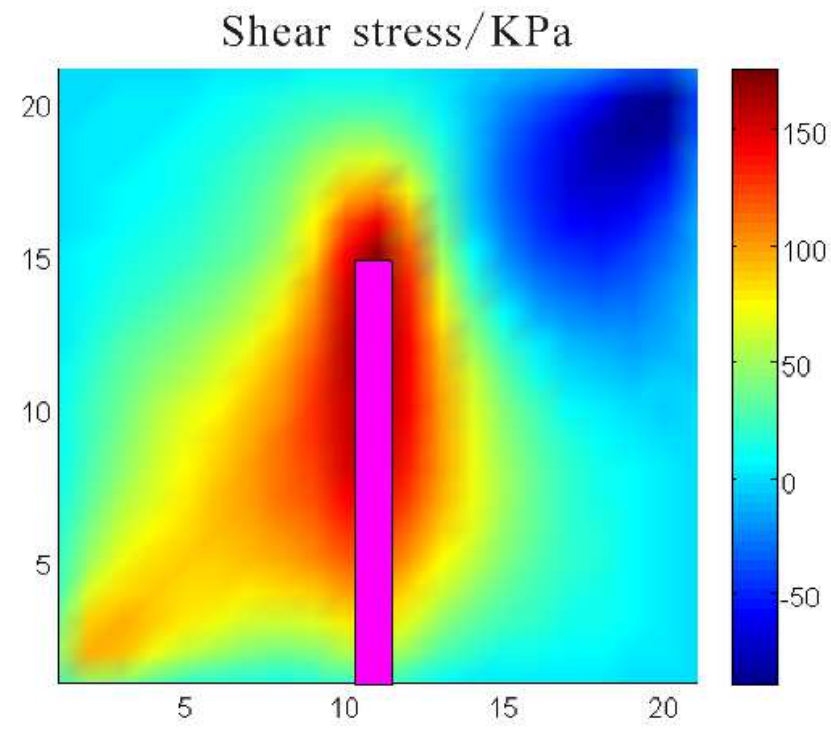

Fig. 5. Shear stress affected by fault 


\section{Effect of Fault on Shear Stress}

Figure 5 shows the distribution of shear stress in the formation. It can be seen from the figure that a larger shear stress is formed near the fault and the maximum value appears at the end of the fault $(\mathrm{G})$. Therefore, shear deformation is more likely to occur in the vicinity of the fault, resulting in the formation of shear slip. If there is a weak structural plane in the formation, it is easier for the formation to slip between layers.

\section{The Seepage and Stress Field near the Fault}

The influence of fault on reservoir is mainly manifested in the independence of stress field and seepage field. This is the main cause of the seepage field and stress field imbalance on both sides of the fault. The distribution of seepage field and stress field in the vicinity of the fault has its own independence. In order to analyze the characteristics of near fault, the attributes of three parts of the fault, the front (point $\mathrm{A}$ to point $\mathrm{D}$ in Fig. 1, the posterior (point $\mathrm{C}$ to $\mathrm{F}$ in Fig. 1) and internal (point $\mathrm{B}$ to point $\mathrm{E}$ in Fig. 1) were analyzed.

\section{The Distribution of Pore Pressure near Fault}

Figure 6 shows the distribution of pore pressure around the fault. From the figure, the pressure of the front fault is greater than that of the rear side. The difference in pressure between point $\mathrm{E}$ and $\mathrm{F}$ is the largest and then gradually reduced. Compared with nofault model, the biggest pressure difference is $2.95 \mathrm{MPa}$ higher at front fault at D and $1.03 \mathrm{MPa}$ lower at rear fault at $\mathrm{F}$ and the biggest pressure difference of two sides of fault model is $3.98 \mathrm{MPa}$. The pore pressure decreases gradually from D to A in front of the fault. On the contrary, the pore pressure increases gradually from point $\mathrm{F}$ to $\mathrm{C}$ at the rear fault. After the fault end (point $\mathrm{G}$, as shown in the dashed line), the values of both tend to be consistent. In order to determine the influence of the fault, the model without fault is simulated under the same condition and the pressure of equivalents is obtained. The results show that the pore pressure without fault is larger than that of rear fault and smaller than that of the front fault of reservoir model. At the same time, due to the existence of the fault, the pore pressure after point $\mathrm{G}$ increase compared with model without fault.

\section{The Distribution of Stress Field near Fault}

The dependence of stress field caused by fault provides a big stress difference on two sides of fault. Figure 7 illustrates that the geo-stress of front fault is bigger than that of rear fault before fault end and tends to be consistent finally after fault end. As is shown in the figure, the biggest stress difference has increased to $1.633 \mathrm{MPa}$. An equivalent model without fault is carried out. The results show that the stress of front fault becomes $1.5 \mathrm{MPa}$ bigger due to fault. However, there is no significance influence on the stress of rear fault by fault. Besides, the stress after fault end $(\mathrm{G})$ of fault model are bigger than that of nofault model. Besides, the stress of fault model increases by $0.365 \mathrm{MPa}$ compared with no-fault model at the region after fault end.

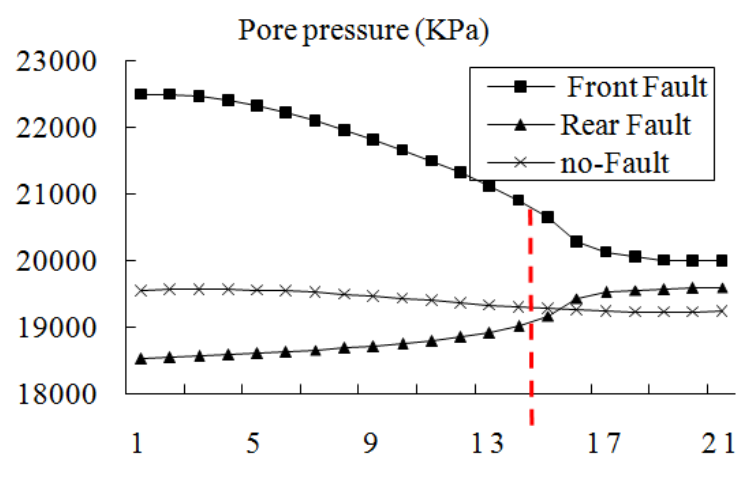

Fig. 6. Chart for pore pressure

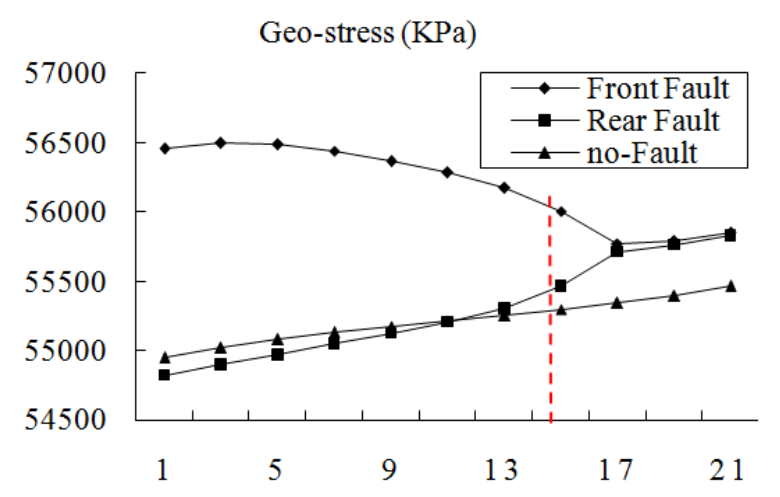

Fig. 7. Chart for geo-stress

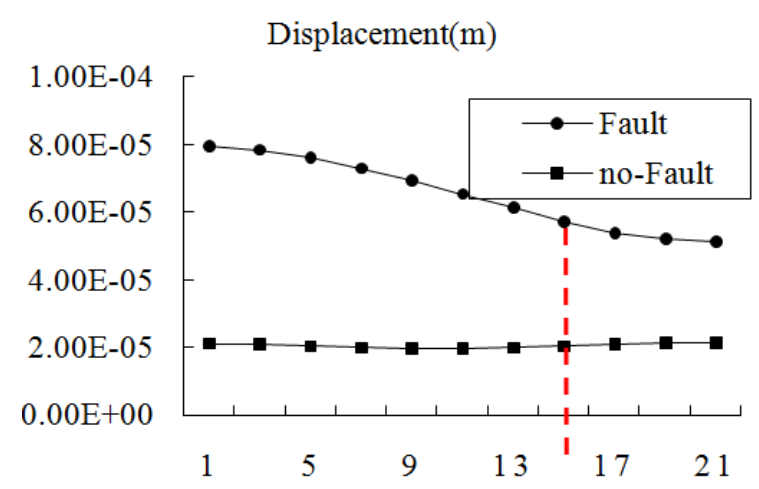

Fig. 8. Displacement of faults 


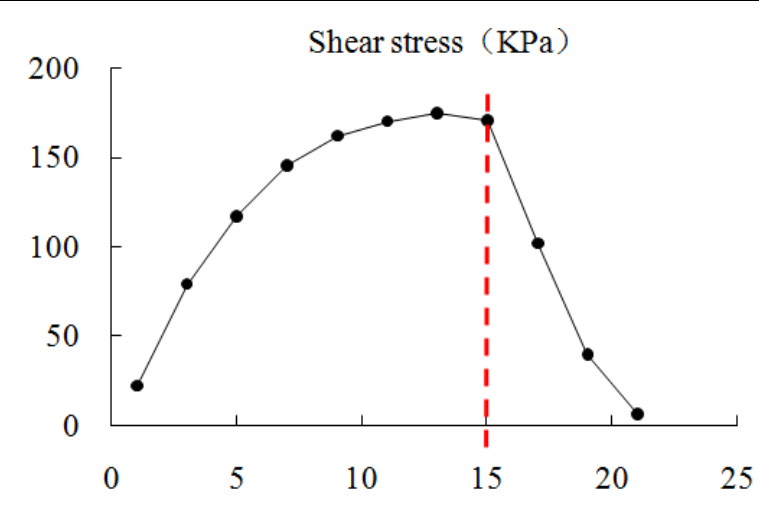

Fig. 9. Shear stress around fault

\section{The Distribution of Displacement near Fault}

The formations move from high stress region to low stress region under the condition that the pore pressure and stress are different on two sides of fault. Figure 8 illustrates the displacements between point $\mathrm{B}$ and $\mathrm{E}$ of fault model and no-fault model. The figures shows that the displacement of fault model becomes larger than that of no-fault model and, in this study, the displacement of fault model is 4 times of no-fault model at point B. Besides, for both two models, the biggest displacement is at point $\mathrm{B}$, while the smallest at point $E$. Therefore, the fault increases the displacement of formation.

\section{The Distribution of Shear Stress near Fault}

As is shown at Fig. 5, the high shear stress region is near the fault. Figure 9 is the distribution of shear stress from B and E. it can be seen that the shear stress increases from $B$ to point $G$ and decreases from $\mathrm{G}$ to E. So, the biggest shear stress is at the fault end (G). To sum up, the high shear stress region near the fault is at the fault end, where is the transition of the impermeable formation and permeable formation. Therefore, shear damages of casing always were found around faults.

\section{Conclusion}

Based on fluid solid coupling theory, a numerical reservoir model of fault containing an injection well and a producing well was established. Then, the influence of fault on seepage pathway, pore pressure and stress of formation was analyzed and, the distribution of seepage field and stress field near the fault were discussed in this study. The main conclusions are as follows.

The seepage pathways are blocked by closed fault and the fluid migration through the new seepage pathways. The pathways become longer and complexity because of closed fault.
The stress field and pressure field are independent on two sides of fault. The pore pressure of front fault is higher than that of rear fault. The pressure shows big difference at front fault while stable at rear fault. Compared pressure of fault model with no-fault model, the biggest pressure difference is $2.95 \mathrm{MPa}$ higher at front fault and $1.03 \mathrm{MPa}$ lower at rear fault and the biggest pressure difference on two sides of fault model is $3.98 \mathrm{MPa}$. Big gradient of geo-stress is found around the injection well and fault. Therefore, the big stress difference on two sides of fault results in deformation and displacement of formation near the fault and the biggest stress difference has increased to 1.633 $\mathrm{MPa}$. The high shear stress region near the fault is at the fault end, where is the transition of the impermeable formation and permeable formation.

At front sides of fault, the pore pressure and geostress diminishes when it closes to the fault end. While, at the rear side of fault, the pore pressure and geo-stress increases when it closes to the fault end. Besides, the value of them are tend to be consistent after fault end. Because of the fault, the stress of fault model increases by $0.365 \mathrm{MPa}$ compared with no-fault model at the region after fault end.

The fault increases the displacement of formation. In this study, the biggest displacement of fault model is 4 times of no-fault model. Therefore, the displacement near faults should be pay more attention to prevent the casing damage.

\section{Acknowledgement}

The research is financially supported by National Natural Science Foundation of China (Grant No. 51174170).And I'd like to express my appreciation to Yuanping Li, Ruiyuan Ma and Zulaing Shao for their discussion about this manuscript.

\section{Funding Information}

The research is financially supported byNational Natural Science Foundation of China (GrantNo. 51174170). Jianjun Liu received the funding.The funders had no role in study design, datacollection and analysis, decision to publish, orpreparation of the manuscript.

\section{Author's Contributions}

Jianjun Liu: Contributed to the conception of the study.

Yongxiang Zheng: Contributed significantly to analysis and manuscript preparation and performed the data analyses and wrote the manuscript.

Bohu Zhang and Yue Sun: Helped perform the analysis with constructive discussions. 


\section{Ethics}

The authors declare that there are not ethical issues that could arise after the publication of this study.

\section{References}

Chao, Z., 2009. Research on casing damage mechanism of steam flooding well group based on numerical simulation. Doctoral dissertation, Wuhan Polytechnic University, Wuhan, China.

Elli, M., S. Stanchits, G. Kwiatek and G. Dresen, 2015. Brittle failure and fracture reactivation in sandstone by fluid injection. Eur. J. Environ. Civil Eng., 97: 535-542. DOI: 10.1080/19648189.2014.896752

Guang, L., 2016. Numerical investigation of $\mathrm{CO}_{2}$ storage in hydrocarbon field using a geomechanical-fluid coupling model. Petroleum, 2: 252-257. DOI: $10.1016 /$ j.petlm.2016.06.003

Hongjie, L., C. Hong, W. Haigeng, W. Peiwen and G. Weimin et al., 2015. Study on reasonable water injection pressure of offshore complex fault-block oilfield. Fault-Block Oil Gas Field, 22: 228-233. DOI: $10.6056 /$ dkyqt201502021

Hua, T., W. Ningning, D. Liangliang and Z. Xiaohua, 2016. Affection mechanism research of initiation crack pressure of perforation parameters of horizontal well. Petroleum, 2: 282-288. DOI: 10.1016/j.petlm.2016.05.002

Jalali, M., J.M. Embry, F. Sanfilippo, F.J. Santarelli and M.B. Dusseault, 2016. Cross-flow analysis of injection wells in a multilayered reservoir. Petroleum, 2: 273-281. DOI: 10.1016/j.petlm.2016.05.005

Ji, Y.J., L.S. Cheng, J.J. Liu and D. Liu, 2011. A simulation of casing damage considering THM coupling. Petroleum Sci. Technol., 29: 977-987. DOI: 10.1080/10916460903514923

Jianjun, L., Y. Xianbin and Z. Jinzhou, 2013. Numerical simulation of geostress and pore pressure evolution around oil or water well under different injectionproduction ratio. Math. Problems Eng., 2013: 476-477. DOI: 10.1155/2013/604748

Jianjun, L., S. Rui and C. Mengmeng, 2014. Numerical simulation on hydromechanical coupling in porous media adopting three-dimensional pore-scale model. Scientific World J., 2014: 140206-140206. DOI: $10.1155 / 2014 / 140206$

Liping, L., L.I. Shucai, S. Shi and X.U. Zhenhao, 2011. Water inrush mechanism study of fault activation induced by coupling effect of stress-seepage-damage. Chinese J. Rock Mechan. Eng.. 30: 3295-3304.

Qingbing, Z., H. Juan and Q. Ren, 2011. Causes and preventive measures of casing failure in oil and water wells. Oil and gas field surface engineering.
Rui, S., L. Jianjun and C. Mengmeng, 2016. Single- and two-phase flow simulation based on equivalent pore network extracted from micro-CT images of sandstone core. Springer Plus, 5: 1-10. DOI: $10.1186 / \mathrm{s} 40064-016-2424-\mathrm{x}$

Sun, J., J. Deng, B. Yu and C. Peng, 2015. Model for fracture initiation and propagation pressure calculation in poorly consolidated sandstone during waterflooding. J. Nat. Gas Sci. Eng., 22: 279-291. DOI: $10.1016 /$ j.jngse.2014.12.004

Xianbin, Y., C. Xiaoqing and J. Youjun, 2015. Single factor analysis of casing force based on the numerical simulation. J. Southwest Petroleum Univ., 37: 127-134.

Xiangfeng, L., 2009. Numerical simulation and prevention measures on casing damage of thermal production well. Doctoral dissertation, Wuhan Polytechnic University, Wuhan, China.

Xiaolan, H., L. Jianjun and Y. Chunhe, 2009. Mechanism analysis and numerical simulation of casing's shear failure in water injection oilfield. J. Wuhan Polytechnic Univ., 28; 94-97.

Xiuting, H., Q.F. Li, J.L. Li and Y. Gao, 2010. Mechanism analysis of casing damage induced by high pressure water injection in daqing oilfield. Key Eng. Mater., 417-418: 81-84.

DOI: $10.4028 / w w w . s c i e n t i f i c . n e t / K E M .417-418.81$

Zanjani, M.M., A. Soroush and M. Khoshini, 2016. Two-dimensional numerical modeling of fault rupture propagation through earth dams under steady state seepage. Soil Dynam. Earthquake Eng., 88: 60-71. DOI: 10.1016/j.soildyn.2016.05.012 